\title{
DETERMINANTS OF PHYSICIANS' INTENTION TO COLLECT DATA EXHAUSTIVELY IN REGISTRIES: AN EXPLORATORY STUDY IN BAMAKO'S COMMUNITY HEALTH CENTRES
}

\author{
B. A. LY ${ }^{1}$, M.-P. GAGNON ${ }^{2,3}$, F. LÉGARÉ ${ }^{2,4}$, M. ROUSSEAU ${ }^{2,4}$ and D. SIMONYAN ${ }^{2}$ \\ ${ }^{1}$ Program of Population Health, University of Ottawa, Ottawa, Ontario, Canada, ${ }^{2} \mathrm{CHUQ}$ Research \\ Centre, Laval University, Quebec, Quebec, Canada ${ }^{3}$ Faculty of Nursing, Laval University, Que- \\ bec, Quebec, Canada ${ }_{4}^{4}$ Faculty of Medicine, Laval University, Quebec, Quebec, Canada
}

DOI: http://dx.doi.org/10.4314/gmj.v49i2.5

Corresponding Author: Dr. Birama Apho Ly

E-mail:Bly022@uottawa.ca,ouapholyca@hotmail.com

Conflict of Interest: None declared

\begin{abstract}
SUMMARY
Background: The incomplete collection of health data is a prevalent problem in healthcare systems around the world, especially in developing countries. Missing data hinders progress in population health and perpetuates inefficiencies in healthcare systems.

Objective: This study aims to identify the factors that predict the intention of physicians practicing in community health centres of Bamako, Mali, to collect data exhaustively in medical registries.

Design: A cross sectional study

Method: In January and February 2011, we conducted a study with a random sample of thirty two physicians practicing in community health centres of Bamako, using a questionnaire. Data was analyzed by using descriptive statistics, correlations and linear regression. Main outcomes measures: Trained investigators administered a questionnaire measuring physicians' sociodemographic and professional characteristics as well as constructs from the Theory of Planned Behaviour.

Results: Our results showed that physicians' intention to collect data exhaustively is influenced by subjective norms and by the physician's number of years in practice.

Conclusions: the results of this study could be used as a guide for health workers and decision makers to improve the quality of health information collected in community health centers.
\end{abstract}

Keywords: Physicians' intention, exhaustive data collection, Bamako, Community Health Centre, Missing data

\section{INTRODUCTION}

Healthcare systems around the world grapple with ways to improve decision making. Good decisions depend largely on the quality of health information ${ }^{1,2}$, which itself depends on how data is collected. The most common problem with the collection of health data is missing data. ${ }^{3}$ This issue concerns every country ${ }^{4,5}$ and is the source of poor, delayed or disrupted care and higher risks of harm. ${ }^{4,5}$ In Mali, as in many developing countries, it is recognised that data is collected incompletely ${ }^{6-9}$, especially in medical consultation registries. This study aimed to identify the factors that explain the intention of physicians practicing in the community health centres of Bamako, Mali, to collect data exhaustively in medical registries.

\section{Review of the literature}

According to Smith and colleagues, nearly $14 \%$ of records of patient consultations in primary care in the United States were missing data. ${ }^{4}$ Similarly, in the United Kingdom, Burnett and her colleagues found that key items of clinical data were missing from $15 \%$ of consultations in National Health Service hospital outpatient clinics. ${ }^{5}$ In Mali, as in many developing countries, the health system is still unable to produce complete data. ${ }^{5}$

In Bamako's community health centres, the common method of dealing with missing data is the complete case or list wise method, whereby all records with missing data are systematically deleted. ${ }^{10,11}$ When the prevalence of missing data is high, this method can lead to information bias. ${ }^{10,12}$

Nonetheless, the use of more sophisticated methods to deal with missing data requires qualified human resources, specific materials and software that are unavailable to Bamako's community health centres. For that reason, practicing prevention by collecting data exhaustively seems an effective solution. 
Such an approach requires a good understanding of physicians' intention to adopt the behaviour of collecting data exhaustively as a means of reducing missing data, completing health information and by extension improving both decisions and patient outcomes.

Several recent empirical studies have demonstrated that psychosocial theories can explain the behaviour of healthcare professionals. ${ }^{13-16}$ One of the psychosocial theories most widely used and well assessed is the Theory of Planned Behaviour (TPB). ${ }^{17}$ According to the TPB, human behaviour can be predicted by the strength of a subject's intention to adopt a given behaviour. This intention is influenced by the subject's attitude toward the behaviour, his or her subjective norms, and his/her perception of control over the behaviour. The subject's perception of control can also influence his or her behaviour directly.

\section{STUDY DESIGN AND METHOD}

\section{Study design and population}

This exploratory cross-sectional study was conducted in community health centres in Bamako, Mali, in January and February 2011. The study population consisted of physicians, who had practiced in Bamako's community health centres between January and December, 2010. We excluded physicians who were outside Bamako during the survey period.

\section{Sampling}

We surveyed thirty-two community health centres out of fifty three existing centres in Bamako. We used a two-degree random sampling technique without discount ${ }^{3}$, with the first degree representing community health centres and the second representing physicians. In each of the thirty-two community health centres selected, we then chose one physician, using the same technique to obtain thirty-two physicians among the fifty physicians who were working in these community health centres.

\section{Data collection}

\section{Data collection tools}

Data were collected with a two part questionnaire. The first part solicited descriptive variables: the respondent's place of medical training, the respondent's training in data management, the respondent's number of years in practice, and the number of years the respondent had occupied his or her current post. The second part of the questionnaire was based on the constructs of the TPB (intention, attitude, subjective norm and perception of control).
We developed items for assessing the theoretical constructs by referring to the literature and to existing questionnaires and by talking to physicians practicing in Bamako's community health centres. The number of items for each theoretical construct varied from two to five, and the items were measured on a seven-point Likert scale (range: one to seven). After administering the questionnaire, we estimated each physician's score per construct by calculating the mean of his or her scores for the items for that construct.

We then calculated a mean score for all physicians. Cronbach's alpha coefficients indicated satisfactory internal consistency for subjective norms $(\alpha=0.73)$ and attitude $(\alpha=0.81)$. The correlation of Pearson (r) was 0,58 for the items of intention and 0,48 for those of perception of control.

\section{Data collection process}

Three trained investigators administered the questionnaires to physicians by individual interviews that took place in January and February 2011. At the end of each survey day, a synthesis was organized to review the day's objectives and find solutions to difficulties. For cases of missing or absurd data, the investigators returned to physicians to complete or correct the information.

\section{Data analysis}

We began by conducting descriptive analyses of physicians' characteristics and the four TPB constructs (intention, attitude, subjective norms and perception of control). Next, we used Pearson's correlations coefficients to explore the relationships between physicians' intentions and their characteristics, on one hand, and between their intentions and the TPB constructs, on the other.

To identify factors associated with physicians' intention to collect data exhaustively, we performed a multiple regression analysis with two steps. In the first step, we introduced only the three theoretical determinants of the TPB-namely, attitude, subjective norms and perception of control-into the model. Afterwards, we added those characteristics of physicians that were significantly correlated with intention at $\mathrm{p}<0.05$.

For our regression analysis, we adopted a stepwise procedure whereby we selected the independent variables that made a significant contribution to the prediction of intention. For each variable, the criteria for inclusion and retention in the final model were fixed at $\mathrm{p}<.10$ (inclusion) and $\mathrm{p}<.05$ (retention). 
We respected the postulates of linear regression (namely, the linearity of the relation between intention and the various constructs of the TPB), the normality of errors and homoscedasticity. We performed analyses with the PASW Statistics 18 version of SPSS software.

\section{Institutional review board approval}

This study was approved by the Laval University Ethics Committee (2010-199/ 16-09-2010) and was authorized by Bamako's health regional office (0431/ DRS/ DB). We respected respondents' anonymity and participants gave us their informed consent.

\section{RESULTS}

\section{Physicians' characteristics}

One physician was selected in each of the thirty-two selected community health centres. The thirty-two physicians chosen all accepted to participate to the study. No data was missing. Most participating physicians were men between thirty-one and forty years old. The majority received their medical training in Mali and most had finished their training within the preceding ten years. Most participants declared never having been trained in data management. Participants' average number of years in practice was nearly six, and their average number of years in their current post was 4.4 .

\section{Constructs of the Theory of Planned Behaviour}

Table 1 reports the mean scores and standard deviations of the TPB constructs. Physicians' intention to collect data exhaustively in medical registries was high (6.4 of a maximum of 7$)$. The mean scores for attitude, subjective norms and perception of control were also high (Table 1).

\section{Correlations between intention and theoretical con- structs}

We calculated Pearson's correlations between intention and three TPB constructs, on one hand, and between the three theoretical constructs themselves, on the other. All correlations were moderate or strong and all were significant at $\mathrm{p}<.05$ (Table 2).

\section{Correlation between intention and physicians' char- acteristics}

Only the correlation between intention and physicians' number of years in practice was significant $(\mathrm{p}<.05)$. It was moderate and negative $(-0.37)$. For that reason, our regression model only includes the number of years in practice (Table 3 ).
Table 1 Descriptive Analysis of TPB Constructs

\begin{tabular}{|c|c|c|c|}
\hline Construct & Item & Mean & $\begin{array}{l}\text { Standard } \\
\text { deviation }\end{array}$ \\
\hline \multicolumn{2}{|l|}{ Intention } & 6.40 & 0.71 \\
\hline & $\begin{array}{l}\text { I would qualify my inten- } \\
\text { tion to collect data ex- } \\
\text { haustively in registries as } \\
\text { very low or very strong }\end{array}$ & 6.13 & 1.10 \\
\hline & $\begin{array}{l}\text { Over the coming months, I } \\
\text { intend to begin collecting } \\
\text { data exhaustively in the } \\
\text { registries }\end{array}$ & 6.69 & 0.47 \\
\hline \multicolumn{2}{|l|}{ Attitude } & 6.26 & 0.76 \\
\hline & $\begin{array}{l}\text { To me, collecting data } \\
\text { exhaustively seems very } \\
\text { useless or very useful }\end{array}$ & 6.59 & 0.79 \\
\hline & $\begin{array}{l}\text { To me, collecting data } \\
\text { exhaustively seems very } \\
\text { responsible or very irre- } \\
\text { sponsible }\end{array}$ & 6.56 & 0.80 \\
\hline & $\begin{array}{l}\text { To me, collecting data } \\
\text { exhaustively seems very } \\
\text { pleasant or very unpleasant }\end{array}$ & 6.19 & 0.96 \\
\hline & $\begin{array}{l}\text { To me, collecting } \\
\text { exhaustively seems } \\
\text { gratifying or very } \\
\text { straining }\end{array}$ & 5.66 & 1.51 \\
\hline & $\begin{array}{l}\text { To me, collecting data } \\
\text { exhaustively seems very } \\
\text { satisfactory or very unsat- } \\
\text { isfactory }\end{array}$ & 6.31 & 8.21 \\
\hline \multicolumn{2}{|c|}{ Subjective norm } & 6.44 & 0.59 \\
\hline & $\begin{array}{l}\text { The people most important } \\
\text { to me would strongly } \\
\text { approve or disapprove of } \\
\text { my collecting data ex- } \\
\text { haustively }\end{array}$ & 6.53 & 0.67 \\
\hline & $\begin{array}{l}\text { My colleagues at CSCOM } \\
\text { would strongly approve or } \\
\text { disapprove of my collect- } \\
\text { ing data exhaustively }\end{array}$ & 6.44 & 0.80 \\
\hline & $\begin{array}{l}\text { The intermediate level } \\
\text { would strongly approve or } \\
\text { disapprove of my collect- } \\
\text { ing data exhaustively }\end{array}$ & 6.75 & 0.62 \\
\hline & $\begin{array}{l}\text { The national level would } \\
\text { strongly approve or disap- } \\
\text { prove of my collecting } \\
\text { data exhaustively }\end{array}$ & 6.72 & 0.58 \\
\hline & $\begin{array}{l}\text { Patients would strongly } \\
\text { approve or disapprove of } \\
\text { my collecting data ex- } \\
\text { haustively }\end{array}$ & 5.78 & 1.38 \\
\hline \multicolumn{2}{|c|}{ Perception of control } & 6.48 & 0.5 \\
\hline & $\begin{array}{l}\text { In future, I feel that I will } \\
\text { be able to collect data } \\
\text { exhaustively }\end{array}$ & 6.66 & 0.54 \\
\hline & $\begin{array}{l}\text { In future, there are no } \\
\text { obstacles to me collecting } \\
\text { data exhaustively }\end{array}$ & 6.31 & 0.78 \\
\hline
\end{tabular}


Table 2 Correlations between Intention and TPB Constructs

\begin{tabular}{|l|l|l|l|l|}
\hline Scale & Intention & Attitude & $\begin{array}{l}\text { Subjective } \\
\text { Norm }\end{array}$ & $\begin{array}{l}\text { Perception } \\
\text { of control }\end{array}$ \\
\hline Intention & - & & & \\
\hline Attitude & $0.41^{*}$ & - & & \\
\hline $\begin{array}{l}\text { Subjective } \\
\text { norm }\end{array}$ & $0.53 * *$ & $0.74 * *$ & - & - \\
\hline $\begin{array}{l}\text { Perception } \\
\text { of control }\end{array}$ & $0.43^{*}$ & $0.47 * *$ & $0.39 *$ & - \\
\hline
\end{tabular}

* Correlation is significant at 0.05 (bilateral)

** Correlation is significant at 0.01 (bilateral)

\section{Regression analysis}

The results indicate that the intention of physicians practicing in Bamako's community health centres to collect data exhaustively in medical registries is influenced by their subjective norms $(p<.002)$ and by their number of years in practice $(\mathrm{p}<.03)$. The final regression model explains $38 \%$ of the variance in physicians' intention (Table 4).

Table 3 Correlations between Intention and Physicians' Characteristics

\begin{tabular}{|c|c|c|c|c|c|c|c|}
\hline & Intention & Place of training & $\begin{array}{l}\text { Data manage- } \\
\text { ment training }\end{array}$ & $\begin{array}{l}\text { Years in prac- } \\
\text { tice }\end{array}$ & $\begin{array}{l}\text { Years in } \\
\text { current post }\end{array}$ & Age & Sex \\
\hline Intention & 1 & & & & & & \\
\hline Place of training & -0.06 & 1 & & & & & \\
\hline Data management training & -0.19 & 0.17 & 1 & & & & \\
\hline Years in practice & $-0.37 *$ & 0.29 & 0.14 & 1 & & & \\
\hline Years in current post & -0.08 & 0.008 & 0.15 & $0.75^{* *}$ & 1 & & \\
\hline Age & -0.23 & $0.45^{*}$ & 0.25 & $0.64 * *$ & $0.38^{*}$ & 1 & \\
\hline Sex & -0.15 & 0.29 & 0.25 & $0.44 *$ & 0.35 & $0.48 * *$ & 1 \\
\hline
\end{tabular}

* Correlation is significant at 0.05 (bilateral)

** Correlation is significant at 0.01 (bilatéral)

Table 4 Regression coefficients

\begin{tabular}{|l|l|l|l|l|l|}
\hline \multirow{2}{*}{} & \multicolumn{2}{|l|}{$\begin{array}{l}\text { Non-standardised } \\
\text { coefficients }\end{array}$} & $\begin{array}{l}\text { Stand- } \\
\text { ardised } \\
\text { coeffi- } \\
\text { cients }\end{array}$ & total & p value \\
\cline { 2 - 6 } & $\mathbf{A}$ & $\begin{array}{l}\text { Standard } \\
\text { error }\end{array}$ & Beta & & \\
\hline Constant & 2.94 & 1.15 & & 2.55 & 0.016 \\
\hline $\begin{array}{l}\text { Subjec- } \\
\text { tive norm }\end{array}$ & 0.58 & 0.17 & 0.49 & 3.34 & 0.002 \\
\hline $\begin{array}{l}\text { Number } \\
\text { of years } \\
\text { in prac- } \\
\text { tice }\end{array}$ & -0.05 & 0.02 & -0.32 & - & 0.03 \\
\hline
\end{tabular}

\section{DISCUSSION}

The purpose of this study was to identify factors that predict physicians' intention to collect data exhaustively in medical consultation registries. To the best of our knowledge, this study is the first to use the TPB to study physicians' intention to collect data exhaustively.

It is also among the few studies to explore physician behaviours likely to influence the quality of health data collected in developing countries, especially data collected in community health centres.

These centres are the least centralized structures in the healthcare system pyramid and could play an important role in improving the quality of health information and, consequently, the quality of health decisions. Our use of the TPB, a model recognized for its efficacy in the study of the behaviour and intentions of healthcare $\operatorname{professionals}^{15}$, allowed us to explain $38 \%$ of physi- cians' intentions in our sample. In bivariate analyses, physicians' intention was correlated positively with attitude, subjective norms and perception of control, and negatively with their number of years in practice.

However, our final linear regression model only included subjective norms and the number of years in practice. Several studies carried out with healthcare professionals - often physicians-have indicated the importance of subjective norms in the prediction of intention. ${ }^{14,16,18-21}$ For example, Kortteisto et al. indicate that subjective norms were a key factors in the prediction of healthcare professionals' intention to use clinical practice guidelines in their speciality field to make decisions concerning patients care. ${ }^{20}$

Foy et al. indicate that subjective norms contribute to predict healthcare professionals' intention to determine patients' knowledge, to use explicit terminologies and to investigate the meaning of diagnoses for patients. ${ }^{14}$

$\mathrm{Wu}$ et al found that subjective norms had the biggest effect on healthcare professionals' intention to use a report system of unwanted events. ${ }^{21}$ Similarly, Hrisos et al. demonstrated that subjective norms were an important factor in the prediction of physicians' intention to inspect diabetics' feet and to prescribe statine. ${ }^{16}$ Finally, Khanna et al. indicate that the subjective norms are one of the factors which explain physicians' intention to measure the body mass index of children and teenagers. ${ }^{19}$ 
These studies are in line with the results of our study, in which respondents' answers suggest that the other physicians at the community health centres, decisionmakers at intermediate and national levels, and patients all have an important influence on respondents' intention to collect data exhaustively.

Their implication in the process of data collection should probably contribute to promote exhaustive data collection in the physicians' registers. However, the terms of their implication should be better studied to determine the best interventions aimed at exhaustive data collection. Other studies have found that perception of control is the main predictor of physicians' intention to perform various professional behaviours. ${ }^{20},{ }^{22}$ For example, Kortteisto et al. have shown that the most important factor in the prediction of doctors' intention to use clinical practice guideline was perception of control, whereas the most important factor in the prediction of nurses' intention to use it was subjective norm. $^{20}$

Rashidian and Russel have shown that physicians' intention to respect the guidelines of recommended prescriptions was explained by perception of control and attitude, but not by subjective norm. ${ }^{22}$ However, these results should be compared to our results with caution, because the targeted behaviours are different and are studied in different contexts.

As for how experience impacts physicians' intentions, the research is rare; nonetheless, adding this variable to our model explained approximately $10 \%$ of additional variance in intention. Overall, the results demonstrated the level of physicians' intention to be inversely proportional to their number of years in practice. Thus, physicians with the least years in practice scored highest for intention.

Several assumptions could explain this result. The first one is the lack of time ${ }^{23}$ related to workload. Physicians with several years in practice have, generally, more responsibilities (administration and management) in the community health centre than those with few years in practice. They are regularly invited to seminaries and trainings which could reduce their time for registers and data collection. The second assumption is negligence. $^{23}$

Physicians could develop, over the years, negligence to collect data exhaustively when they are not supervised or do not receive feedback on data quality from their superiors. The third assumption is the lack of motivation. ${ }^{24}$ Physicians could lose motivation over the years. Among the factors that cause physicians to lose motivation, low income and poor working conditions are often cited. $^{25-29}$
To find additional income and better working condition, physicians abandon their activities in community health centres for practicing in private centres and let community heath centres's activities to younger physicians. However, additional studies are necessary to verify these assumptions and investigate other assumptions, which can explain why physicians with less than five years in practice have the highest intention to collect data exhaustively in registers.

These results are very important for elaboration, planning and programming policies. Thus, they will be useful for decision-makers, researchers, communities and patients. For example, the decision-makers could use these results to allocate in the posts requiring medical data collection the physicians with less than five years in practice. They could also use these results to prioritize physicians with more than five years in practice for data management training. They could, equally, integrate the normative beliefs into interventions aiming at improvement of data collection quality.

\section{Strengths and limitations of the study}

The main strengths of this study are, first, the use of a structured survey method; second, the random selection of participants; third, an answer rate of $100 \%$, indicating that all of the physicians approached by our investigators answered the questionnaire; and fourth, the absence of missing data. Our results should nonetheless be interpreted with caution, in that the study concerned physicians' intentions rather than their actual behaviour. This said, according to the TPB, intention is a precursor of behaviour ${ }^{17}$ and measures of intention are frequently used to estimate behaviour. ${ }^{13}$

Another element for caution is that we found no study on the determinants of physicians' intention to collect data exhaustively, to which we could compare our results. In addition, our sample size was limited and our limited resources prevented us from verifying the temporal stability of the instrument (test - retest). Also, the questionnaire was administered through face-to-face interviews, which can engender a social desirability bias. Beside, according to Ajzen, the formulation of questions to measure TPB's determiners should integrate the notions of action, target, context and time. ${ }^{17}$

These could not generalize to all questions of our questionnaire. Finally, the developed questionnaire should be more amply validated, especially, in various contexts, to make sure of its utility to measure healthcare professionals' intention to collect data exhaustively. 
These caveats notwithstanding, the regression model's explanation of almost $40 \%$ of the variance in physicians' intention shows the TPB to be a useful model for further exploring the determinants of physicians' intention to collect data exhaustively in medical registries.

\section{Implications for practice}

Our results are important for designing strategies to improve the quality of health data. More specifically, they suggest that physicians' data collection efforts must be supported by their colleagues at the community health centre, by decision makers at the intermediate and national levels, and by patients. They also suggest that decision makers should consider assigning younger physicians to posts requiring data collection. Decision makers should also consider training physicians with more than five years in practice, in data collection techniques.

\section{Directions for future research}

This is a pilot study. For future research, the questionnaire should be amply validated in various contexts to ensure its validity and its reliability in measuring physicians' intention to collect data exhaustively. New studies would need larger samples to ensure sufficient power.

\section{CONCLUSION}

The findings of this study can help drive interventions to promote exhaustive data collection and thereby improve the quality of health information and healthrelated decisions.

The findings can also inform the allocation of resources, for example by assigning data-collection tasks to younger doctors.

Finally, the findings provide basic information for future research on physicians' intention to collect data exhaustively in different contexts.

\section{ACKNOWLEGMENTS}

We would like to sincerely acknowledge the physicians of community health centres of Bamako for consenting to participate in the study, the members of medical region direction of Bamako for their contribution, our investigators for their effort, and the members of CRCHUQ for their support and encouragement.

\section{REFERENCES}

1. AbouZahr C, Boerma T. Health information systems: the foundations of public health. Bull World Health Organ. 2005; 83: 578-83.

2. Evans T, Stansfield S. Health information in the new millennium: a gathering storm? Bull World Health Organ. 2003; 81:856.
3. Ancelle T, editor. Statistique Épidémiologie. 2e ed. Paris: Édition Maloine; 2006.

4. Smith PC, Araya-Guerra R, Bublitz C, Parnes B, Dickinson LM, Van Vorst R, et al. Missing Clinical Information During Primary Care Visits. JAMA. 2005; 293 (5):565-71.

5. Burnett SJ, Deelchand V, Franklin BD, Moorthy $\mathrm{K}$, Vincent $\mathrm{C}$. Missing Clinical Information in NHS hospital outpatient clinics: prevalence, causes and effects on patient care. BMC Health Serv Res. 2011;11(114).

6. Ministère de la santé du Mali. Système Local d'Information Sanitaire. Mali: Direction Nationale de la Santé. 2007.

7. Ministère de la santé du Mali. Système national d'information sanitaire (SNIS): annuaire 2009. Bamako, Mali. 2010.

8. Réseau de Métrologie Sanitaire. Rapport d'évaluation du système d'information sanitaire du Sénégal. Sénégal. 2007.

9. Réseau de Métrologie Sanitaire. Rapport d'évaluation du Système d'Information Sanitaire à l'aide de l'outil HMN. Burundi. 2008.

10. Lubeck DP, Pasta DJ, Flanders SC, Henning JM. Approaches to Missing Data Inference Results from CaPSURE: An Observational Study of Patients with Prostate Cancer. Pharmacoeconomics. 1999; 15 (2):197-204.

11. Vach W, Blettner M. Biased estimation of the odds ratio in case-control studies due to the use of ad hoc methods of correcting for missing values for confounding variables. Am. J. Epidemiol. 1991; 134 (8): 895-907.

12. Fox-Wasylyshyn SM, El-Masri MM. Focus on research methods: handling missing data in selfreport measures. RINAH. 2005; 28: 488-95.

13. Eccles MP, Hrisos S, Francis J, Kaner EF, Dickinson HO, Beyer F, et al. Do self-reported intentions predict clinicians' behaviour: a systematic review. Implement Sci. 2006; 1: 28.

14. Foy R, Bamford C, Francis JJ, Johnston M, Lecouturier J, Eccles M, et al. Which factors explain variation in intention to disclose a diagnosis of dementia? A theory-based survey of mental health professionals. Implement Sci. 2007; 2 (31).

15. Godin G, Belanger-Gravel A, Eccles M, Grimshaw J. Healthcare professionals' intentions and behaviours: A systematic review of studies based on social cognitive theories. Implement Sci. 2008; 3: 36 .

16. Dijkstra R, Johnston M, et al. Using psychological theory to understand the clinical management of type 2 diabetes in Primary Care: a comparison across two European countries. BMC Health Serv Res. 2009; 9 (140). 
17. Ajzen I. The theory of planned behavior. Organ Behav Hum Decis Process. 1991; 50: 179-211.

18. Foy R, Walker A, Ramsay C, Penney G, Grimshaw J, Francis J. Theory-based identification of barriers to quality improvement: induced abortion care. Int J Qual Health Care. 2005; 17 (2): 147-55.

19. Khanna R, Kavookjian J, Scott VG, Kamal KM, Miller LAN, Neal WA. Using the theory of reasoned action to determine physicians' intention to measure body mass index in children and adolescents. Res Social Adm Pharm. 2009; 5: 170-81.

20. Kortteisto T, Kaila M, Komulainen J, Mäntyranta $T$, Rissanen P. Healthcare professionals' intentions to use clinical guidelines: a survey using the theory of planned behaviour. Implement Sci. 2010; 5 (51).

21. Wu JH, SHen WS, Lin LM, Greenes R, Bates DW. Testing the technology acceptance model for evaluating healthcare professionals' intention to use an adverse event reporting system. Int $J$ Qual Health Care. 2008; 20 (2):123-9.

22. Rashidian A, Russell I. Intentions and statins prescibing: can the theory of planned behaviour explain physician behaviour in following guideline recommendations? J Eval Clin Pract [serial on the Internet]. 2011: Available from: http://onlinelibrary.wiley.com/doi/10.1111/j.13652753.2011.01690.x/full.

23. Buhi ER, Goodson P, Neilands TB. Out of Sight, Not Out of Mind:Strategies for Handling Missing Data. Am J Health Behav. 2008; 32 (1): 83-92.
24. De Bonnières A, Estryn-Behar M, Lassaunière JM. Déterminants de la satisfaction professionnelle des médecins et infirmières de soins palliatifs. Médecine palliative: Soins de support - Accompagnement - Éthique. 2010; 9: 167-76.

25. Dieleman M, Cuong PV, Anh LV, Martineau T. Identifying factors for job motivation of rural health workers in North Viet Nam. Hum Resour Health. 2003; 1:10.

26. Dieleman M, Toonen J, Touré H, Martineau T. The match between motivation and performance management of health sector workers in Mali. Hum Resour Health. 2006; 4 (2):7.

27. Agyepong IA, Anafi P, Asiamah E, Ansah EK, Ashon DA, Narh-Dometey C. Health worker (internal customer) satisfaction and motivation in the public sector in Ghana. Int $J$ Health Plann Mgmt. 2004; 19: 319-36.

28. Henderson LN, Tulloch J. Incentves for retaining and motivating health workers in Pacific and Asian countries. Hum Resour Health. 2008; 6 (18): 20.

29. Willis - Shattuck M, Bidwell P, Thomas S, Wyness L, Blaauw D, Ditlopo P. Motivation and retention of health workers in developing countries: a systematic review. BMC Health Serv Res. 2008; 8 (247):8. 